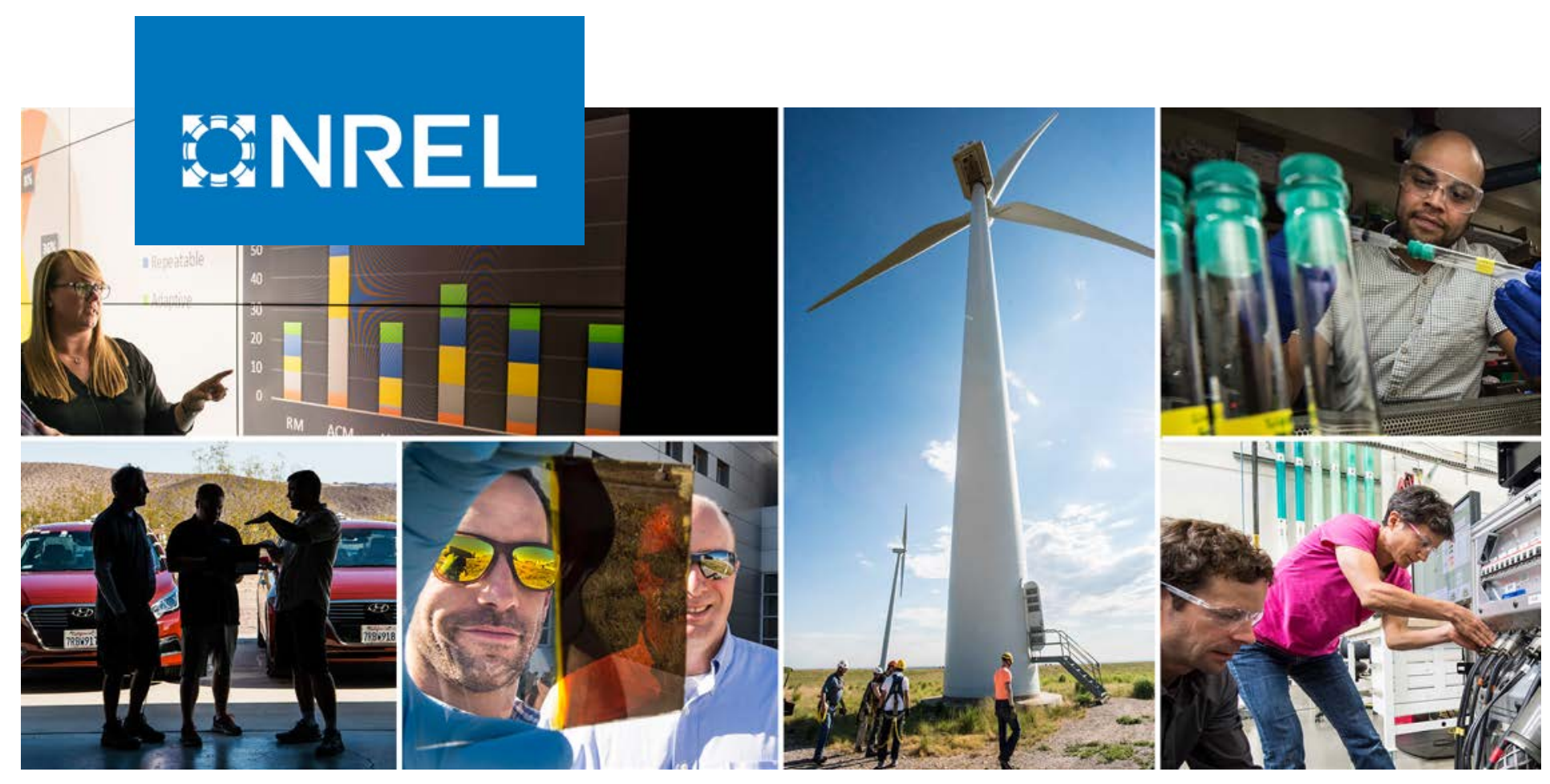

\title{
2019 Anion Exchange Membrane Workshop Summary Report
}

Bryan Pivovar ${ }^{1}$ and Yu Seung Kim ${ }^{2}$

\section{National Renewable Energy Laboratory \\ 2 Los Alamos National Laboratory}

2019 Anion Exchange Membrane Workshop

Dallas, Texas

May 30, 2019

NREL is a national laboratory of the U.S. Department of Energy Office of Energy Efficiency \& Renewable Energy

Operated by the Alliance for Sustainable Energy, LLC

This report is available at no cost from the National Renewable Energy Laboratory (NREL) at www.nrel.gov/publications.
Technical Report

NREL/TP-5900-77240

July 2020 


\title{
GHREL
}

\section{Anion Exchange Membrane Workshop Summary Report}

\author{
Bryan Pivovar ${ }^{1}$ and Yu Seung Kim ${ }^{2}$
}

1 National Renewable Energy Laboratory

2 Los Alamos National Laboratory

\section{Suggested Citation}

Pivovar, Bryan and Yu Seung Kim. 2020. 2019 Anion Exchange Membrane Workshop

Summary Report. Golden, CO: National Renewable Energy Laboratory. NREL/TP-5900-

77240. https://www.nrel.gov/docs/fy20osti/77240.pdf.

NREL is a national laboratory of the U.S. Department of Energy Office of Energy Efficiency \& Renewable Energy Operated by the Alliance for Sustainable Energy, LLC

This report is available at no cost from the National Renewable Energy Laboratory (NREL) at www.nrel.gov/publications.

Contract No. DE-AC36-08GO28308
Technical Report NREL/TP-5900-77240 July 2020

National Renewable Energy Laboratory 15013 Denver West Parkway Golden, CO 80401 303-275-3000 • www.nrel.gov 


\section{NOTICE}

This work was authored in part by the National Renewable Energy Laboratory, operated by Alliance for Sustainable Energy, LLC, for the U.S. Department of Energy (DOE) under Contract No. DE-AC36-08GO28308. Funding provided by U.S. Department of Energy Office of Energy Efficiency and Renewable Energy Fuel Cell Technologies Office. The views expressed herein do not necessarily represent the views of the DOE or the U.S. Government.

This report is available at no cost from the National Renewable Energy Laboratory (NREL) at www.nrel.gov/publications.

U.S. Department of Energy (DOE) reports produced after 1991 and a growing number of pre-1991 documents are available free via www.OSTI.gov.

Cover Photos by Dennis Schroeder: (clockwise, left to right) NREL 51934, NREL 45897, NREL 42160, NREL 45891, NREL 48097, NREL 46526.

NREL prints on paper that contains recycled content. 


\section{Acknowledgements}

The 2019 Anion Exchange Membrane Workshop was held Thursday, May 30, 2019, at the Sheraton Dallas Hotel in Dallas, Texas.

\section{Lead Organizers}

Bryan Pivovar

Yu Seung Kim

\section{Organizing Committee}

Donna Ho

Simon Thompson

Dimitrios Papageorgopoulos Fuel Cell Technologies Office

Mark Pouy

Grigorii Soloveichik

\section{Breakout Session Chairs}

Michael Hickner

Chulsung Bae

Mike Yandrasits

John Kopasz

Yu Seung Kim

Adam Weber

Bill Mustain
National Renewable Energy Laboratory

Los Alamos National Laboratory

Fuel Cell Technologies Office

Fuel Cell Technologies Office

Advanced Research Projects Agency-Energy

Advanced Research Projects Agency-Energy
Penn State University

Rensselaer Polytechnic Institute

$3 \mathrm{M}$

Argonne National Laboratory

Los Alamos National Laboratory

Lawrence Berkeley National Laboratory

University of South Carolina 


\section{Executive Summary}

The National Renewable Energy Laboratory, in coordination with the U.S. Department of Energy Fuel Cell Technologies Office (FCTO), Advanced Research Projects Agency-Energy (ARPA-E), and Los Alamos National Laboratory, hosted the 2019 Anion Exchange Membrane Workshop at the Sheraton Dallas Hotel in Dallas, Texas, on May 30, 2019. More than 50 industrial, academic, national laboratory, and government experts representing the needs of anion exchange membranes (AEMs), membrane electrode assemblies (MEAs), and system and stack components attended the workshop.

This workshop was meant to build on previous alkaline membrane fuel cell workshops (FCTO 2016; Pivovar 2012) that serve as reference materials dealing with the prior existing state of the art, but it was broadened to have a more diverse device focus beyond just fuel cells and additional emphasis on the membrane materials themselves while focusing on recent advances and current concerns. Perhaps the most significant advances in the AEM field have come from a combination of development of novel membranes (which have shown significantly improved properties and durability) and increases in alkaline membrane fuel cell performance and durability (largely associated with improved performance of electrodes). These advances have accelerated considerably over the past few years as novel approaches and increased research and development efforts have occurred.

This one-day workshop included two breakout sessions. The first session focused on membranes and the second session centered on devices. The body of this report details the discussions that occurred within the breakout sessions; highlights are presented here in the Executive Summary.

Within the membrane area, two specific focus areas were investigated: (1) targets and (2) standardized testing methods. The standardized testing methods discussion was split between conductivity measurements and the complications of carbonate formation and all other property measurements. ARPA-E, through its Integration and Optimization of Novel Ion Conducting Solids (IONICS) program, had put forth targets for AEMs, and the discussion of targets revolved around the relevance of these targets and potential modifications (ARPA-E 2016). The suggestions from this breakout group regarding targets and suggested changes are presented in Table ES-1. Further discussion and rationale for these areas are presented in the body of the report. 
Table ES-1. Suggested Changes to ARPA-E IONICS AEM Targets

\begin{tabular}{|c|c|c|}
\hline Metric & ARPA-E Targets & Suggested Change \\
\hline $\begin{array}{l}\text { Membrane chemical } \\
\text { stability (at } \geq 80^{\circ} \mathrm{C} \\
\text { immersed in a } \mathrm{pH} \geq 14 \\
\text { solution) }\end{array}$ & $\begin{array}{l}\geq 1,000 \mathrm{~h} \text { with } \leq 2 \% \text { loss in IEC, } \\
\text { ionic ASR, spectroscopic } \\
\text { measures of membrane state, } \\
\text { and mechanical properties }\end{array}$ & $\begin{array}{l}\geq 1,000 \mathrm{~h} \text { with } \leq 5 \% \text { loss in IEC and } \\
\text { conductivity; should include } \\
\text { spectroscopic characterization }\end{array}$ \\
\hline $\begin{array}{l}\text { Component area over } \\
\text { which property values } \\
\text { are achieved to within } \\
\geq 90 \% \text { uniformity }\end{array}$ & $\geq 100 \mathrm{~cm}^{2}$ & Delete this target or decrease priority \\
\hline $\begin{array}{l}\text { lonic ASR (hydroxide } \\
\text { form, } 80^{\circ} \mathrm{C} \text {, liquid } \\
\text { equilibrated) }\end{array}$ & $\leq 0.04 \Omega-\mathrm{cm}^{2}$ & $\begin{array}{l}\text { No change to } 80^{\circ} \mathrm{C} \text { target } \\
\text { Add a target at } 40^{\circ} \mathrm{C}: 0.04 \Omega-\mathrm{cm}^{2}\end{array}$ \\
\hline $\begin{array}{l}\text { lonic ASR }\left(80^{\circ} \mathrm{C}, \leq 50 \%\right. \\
\mathrm{RH}, \text { under air exposure } \\
\text { [i.e., in presence of } 400 \\
\left.\left.\text { ppm } \mathrm{CO}_{2}\right]\right)\end{array}$ & $\leq 0.08 \Omega-\mathrm{cm}^{2}$ & $\begin{array}{l}\text { Change to a measurement at } 80 \% \mathrm{RH} \\
\text { under } \mathrm{CO}_{2} \text {-free air exposure; keep } \\
\text { target at } \leq 0.08 \Omega-\mathrm{cm}^{2} \text {. }\end{array}$ \\
\hline $\begin{array}{l}\text { Mechanical durability } \\
\text { during humidity cycling }\end{array}$ & $\geq 20,000 \mathrm{RH}$ cycles & Delete this target \\
\hline Electronic ASR & $\geq 1,000 \Omega-\mathrm{cm}^{2}$ & No change proposed \\
\hline Humidity stability factor & $>5$ & No change proposed \\
\hline $\begin{array}{l}\text { Swelling in liquid water } \\
\text { at } 25^{\circ} \mathrm{C}\end{array}$ & $<50 \%$ & $\begin{array}{l}\text { To be measured as linear swell in } \mathrm{X}-\mathrm{Y} \\
\text { plane in water, membrane in } \mathrm{OH}^{-} \text {form }\end{array}$ \\
\hline Pressure differential & $\geq 1$ bar & $\begin{array}{l}\text { Delete for fuel cell and flow battery } \\
\text { applications; electrolyzer industry input } \\
\text { on burst test or other relevant test and } \\
\text { metrics needed }\end{array}$ \\
\hline $\begin{array}{l}\mathrm{H}_{2} \text { crossover and } \mathrm{O}_{2} \\
\text { crossover }\end{array}$ & $\leq 25 \mathrm{nmol} / \mathrm{cm}^{2}-\mathrm{s}$ & $\begin{array}{l}\text { Change to }<5 \mathrm{~mA} / \mathrm{cm}^{2} \text { for } \mathrm{H}_{2} \text { crossover, } \\
\text { eliminate } \mathrm{O}_{2} \text { crossover target }\end{array}$ \\
\hline $\begin{array}{l}\text { Cost for membrane that } \\
\text { can be practically } \\
\text { integrated in a device }\end{array}$ & $\leq 20 \$ / \mathrm{m}^{2}$ & No change proposed \\
\hline $\mathrm{H}_{2} \mathrm{O}$ transport & --- & $\begin{array}{l}\text { New target proposed for water } \\
\text { transport: }>4 \mu \mathrm{mol} / \mathrm{cm}^{2}-\mathrm{s}\end{array}$ \\
\hline Ionic permeability & --- & $\begin{array}{l}\text { New target proposed for flow batteries } \\
\text { to limit permeability of other ions: } \\
<7 \times 10^{-8} \mathrm{~cm}^{2} / \mathrm{s}\end{array}$ \\
\hline
\end{tabular}

IEC: ion exchange capacity

ASR: area specific resistance

$\mathrm{RH}$ : relative humidity 
During the standardized testing methods breakout sessions, the details and conditions under which to run membrane tests were discussed in more detail. A major limiting factor across the board for AEMs is the lack of commercially available membranes and a membrane that is broadly accepted as a baseline. With recent advances and commercialization efforts, this is likely to improve in the near future. The challenges of carbonate formation and testing membranes exposed to the atmosphere were discussed in depth by one breakout group, with emphasis on the challenges of measuring conductivity. Another breakout group focused on the relative importance of membrane properties beyond conductivity and the need for standardized testing protocols. The list of proposed step-wise tests included:

- $\quad 1^{\text {st }}$ round (baseline polymer characterization): mechanical stability, water uptake and swelling ratio, IEC, alkaline stability at $1 \mathrm{M} \mathrm{KOH} / 80^{\circ} \mathrm{C}$

- $\quad 2^{\text {nd }}$ round: electrochemical stability tests that mimic the electrochemical cell conditions (for fuel cell and electrolyzer), RH cycling/RH cycling with mechanical stability (for fuel cell), water permeability (for fuel cell and electrolyzer)

- $\quad 3^{\text {rd }}$ round: pressure cycling test (for electrolyzer), gas crossover (for fuel cell and electrolyzer).

The afternoon breakout sessions focused on the use of AEMs in electrochemical devices. The three breakout session topics were electrode performance; water and $\mathrm{CO}_{2}$ management; and device performance and durability milestones, metrics, and targets.

Perhaps some of the biggest improvements seen in AEM-based devices have come from improved electrode performance. The electrode layer has concerns with water management, mass transfer, and catalyst-ionomer interactions that need to be better understood and further optimized to reach performance and durability levels required for commercial competitiveness. The breakout session discussion revolved around fuel cell and electrolysis operation and the different needs of anode versus cathode in each operating mode. Ultra-low platinum group metal (PGM) (less than $0.125 \mathrm{mg} / \mathrm{cm}^{2}$ ) and PGM-free electrodes were of interest for all cases except for fuel cell anodes, for which PGM-free options of relevance haven't been identified and may be challenging. A need for novel ionomers and tests that screen electrodes and catalyst/ionomer interactions more effectively was discussed. This area has seen significant advancement recently but remains a critical need for further advancing the applicability of AEM devices.

AEM-based devices have water and $\mathrm{CO}_{2}$ management issues that go beyond concerns of proton exchange membrane (PEM)-based devices. These issues can be largely mitigated in electrolysis operation where avoiding ambient $\mathrm{CO}_{2}$ and operating in a flooded, liquid water state reduce concern. However, fuel cell operation is highly impacted by these issues. $\mathrm{CO}_{2}$ exposure (even at atmospheric concentrations) was seen as critically limiting fuel cell performance to a level that prevents commercial applicability, with the only viable option being avoiding exposure to concentrations above single-digit-ppm levels. Water management is more complicated and has limited the robustness (dynamic range of operation, hot/dry vs. cold/wet) of AEM fuel cells. High performance is achievable in these devices, as is reasonable durability under static conditions, but advances are required to allow more dynamic operating conditions. 
AEM device metrics are even less developed than membrane metrics. The focus of this session was on fuel cells, although it was recognized that other devices would also need targets. For now, the fuel cell focus was based on the state of technological advancement of AEM fuel cells and the depth of PEM fuel cell targets for comparison purposes. The general opinion was that the milestones should be set so AEM fuel cells start rivaling PEM fuel cells, and ultimate targets should be set to show AEM fuel cell advantages over PEM fuel cells. The main potential advantage being cost, targets should be set with significantly lower PGM loading. New suggested milestones and targets for AEM fuel cells were discussed and are presented in Table ES-2.

Table ES-2. Suggested Milestones and Targets for AEM Fuel Cells

\begin{tabular}{|l|l|}
\hline \multicolumn{2}{|l|}{ Proposed Milestones } \\
\hline 2021 & $\begin{array}{l}\text { Efficiency: } 100 \mathrm{~mW} / \mathrm{cm}^{2} \text { performance at } 0.8 \mathrm{~V}\left(\mathrm{~T} \geq 80^{\circ} \mathrm{C} \text { ) with } 0.2 \mathrm{mg} \mathrm{PGM}, \mathrm{P} \leq 250\right. \\
\mathrm{kPa}\end{array}$ \\
\hline 2022 & $\begin{array}{l}\text { AEM fuel cell initial performance } 0.65 \mathrm{~V} \text { at } 1,000 \mathrm{~mA} / \mathrm{cm}^{2} \text { on } \mathrm{H}_{2} / \mathrm{O}_{2} \text { (maximum } \\
\text { pressure of } 1.5 \mathrm{~atm}) \text { in } \mathrm{MEA} \text { with total }<0.2 \mathrm{mg} \mathrm{PGM} / \mathrm{cm}^{2} \text { and }<10 \% \text { voltage } \\
\text { degradation over } 1,000 \mathrm{~h}, \mathrm{~T}>80^{\circ} \mathrm{C}\end{array}$ \\
\hline 2023 & $\begin{array}{l}\mathrm{CO}_{2} \text { tolerance: }<65 \mathrm{mV} \text { loss for steady state operation at } 1.5 \mathrm{~A} / \mathrm{cm}^{2} \text { in } \mathrm{H}_{2} / \text { air } \\
\text { scrubbed to } 2 \mathrm{ppm} \mathrm{CO}_{2}\end{array}$ \\
\hline 2024 & $\begin{array}{l}\text { Catalyst durability: } \mathrm{H}_{2} / \mathrm{CO}_{2} \text {-scrubbed air after accelerated stress test }<40 \% \text { loss } \\
\text { after } 10,000 \text { cycles from } 0.6 \mathrm{~V} \text { to } 0.95 \mathrm{~V} \\
\text { Membrane durability: } 1,000 \text {-h open circuit voltage hold at } 70 \% \mathrm{RH} \text { and } \geq 80^{\circ} \mathrm{C}\end{array}$ \\
\hline 2025 & $\begin{array}{l}1 \mathrm{~W} / \mathrm{cm}^{2} \text { at } 0.65 \mathrm{~V} ; \mathrm{H}_{2} / \mathrm{CO}_{2} \text {-free air with total } \mathrm{PGM} \text { loading }<0.125 \mathrm{mg} / \mathrm{cm}^{2}, \mathrm{~T}>80^{\circ} \mathrm{C}, \\
\mathrm{P} \leq 250 \mathrm{kPa}\end{array}$ \\
\hline 2030 & $\begin{array}{l}\mathrm{AEM} \text { fuel cell peak power performance }>600 \mathrm{~mW} / \mathrm{cm}^{2} \text { under } \mathrm{H}_{2} / \mathrm{air}(\mathrm{maximum} \\
\text { pressure of } 1.5 \text { atm) in } \mathrm{PGM} \text {-free MEA }\end{array}$ \\
\hline Ultimate & $1 \mathrm{~W} / \mathrm{cm}^{2}$ at rated power $\left(\sim 0.65 \mathrm{~V}\right.$ at $\left.95^{\circ} \mathrm{C}\right), \mathrm{PGM}$-free MEA, $\mathrm{T} \geq 80^{\circ} \mathrm{C}, \mathrm{P} \leq 250 \mathrm{kPa}$ \\
\hline
\end{tabular}

The advances in membranes and fuel cell performance have been substantial over the past few years. It is anticipated that further advances will be accomplished in the near future as improved materials become more readily available and improved insights into the degradation mechanisms of membranes, electrode structure and performance, and water and $\mathrm{CO}_{2}$ management are achieved. The promise of AEMs is starting to be more fully realized, and AEM devices may outperform PEM-based devices in the near future. Exercises like this workshop are critical for helping bring the community together and accelerate advances of the technology. 


\section{Table of Contents}

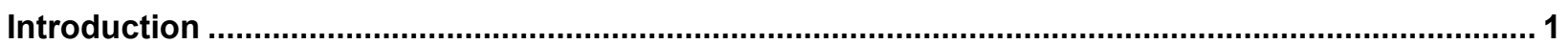

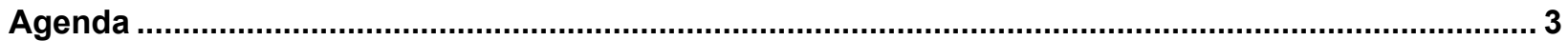

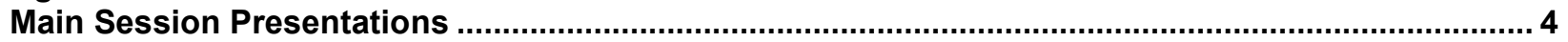

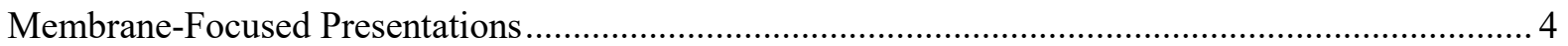

Device-Focused Presentations ....................................................................................... 5

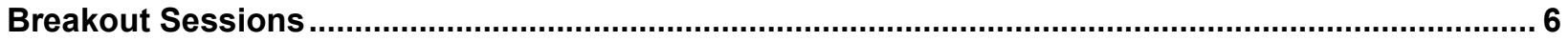

Morning Session: Membrane Focus ............................................................................. 6

Breakout Session 1: Standardized Protocols-Conductivity and $\mathrm{CO}_{2} \ldots \ldots \ldots \ldots \ldots \ldots \ldots \ldots \ldots \ldots \ldots 6$

Breakout Session 2: Standardized Protocols-Degradation, IEC, and Mechanical Properties .... 8

Breakout Session 3: Membrane Metrics and Targets...................................................... 11

Afternoon Session: Device Focus ............................................................................... 15

Breakout Session 1: Electrode Performance .................................................................. 15

Breakout Session 2: Water and $\mathrm{CO}_{2}$ Management....................................................... 18

Breakout Session 3: Device Performance and Durability Milestones, Metrics, and Targets...... 20

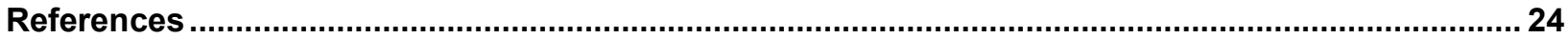




\section{Introduction}

The National Renewable Energy Laboratory (NREL), in coordination with the U.S. Department of Energy (DOE) Fuel Cell Technologies Office (FCTO), Advanced Research Projects AgencyEnergy (ARPA-E), and Los Alamos National Laboratory (LANL), hosted the 2019 Anion Exchange Membrane Workshop at the Sheraton Dallas Hotel in Dallas, Texas, on Thursday, May 30, 2019. This time and location were chosen based on coordination with the 2019 Spring Meeting of the Electrochemical Society (ECS) and an ability to leverage the workshop timing with an anion exchange membrane (AEM) session on Wednesday, May 29.

More than 50 industrial, academic, national laboratory, and government experts representing the needs of AEMs, membrane electrode assemblies (MEAs), and system and stack components attended the workshop. The purpose of this workshop was to bring together the research community to discuss key issues impacting the following topics:

1. Identifying further challenges of AEMs and ionomers toward device development (catalyst/ionomer interactions, water management, and carbonate formation)

2. Baselining of membrane and ionomer materials (selection and manufacturing of standard materials and round robin testing)

3. Testing protocols (application-specific metrics and targets).

This 2019 workshop built on previous alkaline membrane fuel cell workshops held in 2006, 2011 and 2016 (Pivovar 2006; Pivovar 2012; FCTO 2016). The 3-year time gap between this workshop and the last one was more compressed than the 5-year gap between previous workshops; this timing was driven by the accelerating rate of technical advances of the past few years. Additionally, the previous workshops were strictly focused on fuel cells while this workshop had a stronger membrane focus as well as greater consideration for other electrochemical devices that employ AEMs (including water electrolyzers, flow batteries, and $\mathrm{CO}_{2}$ electrolyzers). This workshop also had the participation of ARPA-E as a co-organizer, reflecting the emphasis of ARPA-E on AEMs within its Integration and Optimization of Novel Ion Conducting Solids (IONICS) program.

The continued growing interest in alkaline membrane fuel cells is reflected in Figure 1, which shows search results using the Scopus search engine with the search terms "alkaline membrane" and "fuel cell" for the years 2004 to 2018. (From 1991 to 2003, Scopus yielded only four hits.) The advances over the past 3 years, discussed throughout this report, were a primary motivation for the workshop itself. 


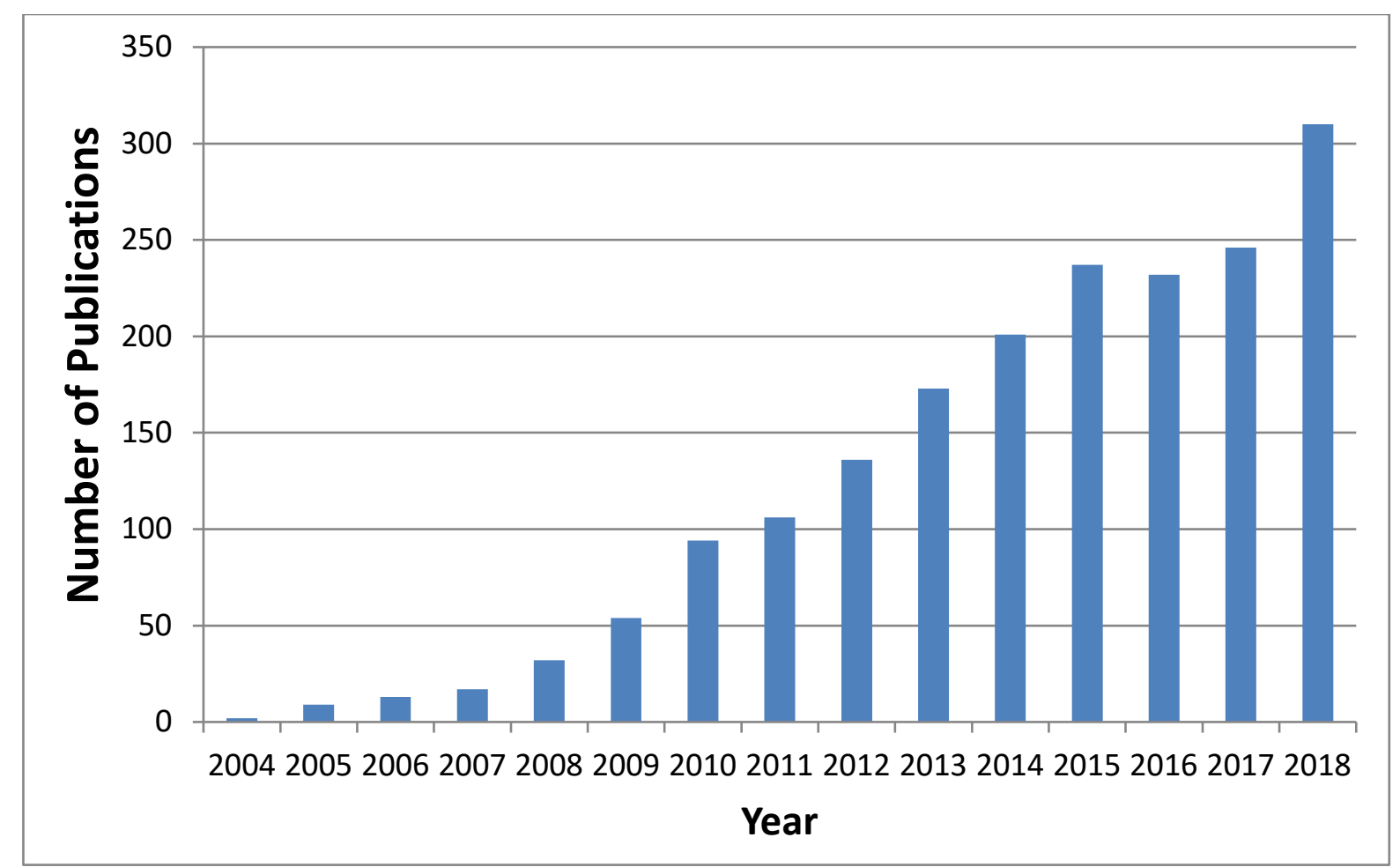

Figure 1. Publications with "alkaline membrane" and "fuel cell" from the Scopus search engine

The agenda for the workshop, overviews of the main session presentations, and summaries of the breakout sessions are presented in the following sections. 


\section{Agenda}

8:00-8:20 Opening Remarks, Donna Ho (FCTO) and Grigorii Soloveichik (ARPA-E)

8:20-8:40 Workshop Overview and AEM Status, Bryan Pivovar (NREL)

8:40-9:05 Membrane Targets and Metrics, Mark Pouy (ARPA-E)

9:05-9:30 Membrane Testing Challenges, Standardization, Mike Yandrasits (3M)

9:30-9:45 Break

9:45-11:45 Morning Breakout Sessions (AEM Focus)

1. Standardized Protocols-Conductivity and $\mathrm{CO}_{2}$ (Mike Hickner)

2. Standardized Protocols-Degradation, Ion Exchange Capacity, and Mechanical Properties (Chulsung Bae)

3. Membrane Metrics and Targets (John Kopasz, Mike Yandrasits)

11:45-12:45 Working Lunch—Outbriefs from Morning Breakout Sessions, Group Discussion

12:45-1:15 Anion Exchange Membrane Milestones, Performance and Durability Status, Bill Mustain (University of South Carolina)

1:15-1:45 Catalyst-Ionomer Interactions, AEM Fuel Cell Durability, Yu Seung Kim (LANL)

2:00-3:45 Afternoon Breakout Sessions (AEM Device Focus)

1. Electrode Performance (Yu Seung Kim)

2. Water and $\mathrm{CO}_{2}$ Management (Adam Weber)

3. Device Performance and Durability Milestones, Metrics, and Targets (John Kopasz, Bill Mustain)

3:45-4:00 Break

4:00-5:00 Joint Session Outbrief from Afternoon Breakout Sessions, Group Discussion

5:00 Concluding Remarks 


\section{Main Session Presentations}

Opening remarks were presented by Donna Ho (FCTO) and Grigorii Soloveichik (ARPA-E).

Bryan Pivovar (NREL) presented an overview of the 2019 AEM Workshop and a brief summary of AEM status, including content from the 2016 Alkaline Membrane Fuel Cell Workshop findings. Additional AEM status was presented the day before the workshop as part of the 2019 Spring ECS Meeting proceedings, so the invited talks were limited to focused presentations specifically relevant to the breakout sessions.

Before the morning membrane-focused breakout sessions, Mark Pouy (ARPA-E) presented an overview on membrane metrics/targets, and Mike Yandrasits (3M) presented on membrane testing challenges and standardization. Before the afternoon device-focused breakout sessions, Bill Mustain (University of South Carolina) presented on AEM fuel cell (AEMFC) performance and durability milestones and status and Yu Seung Kim (LANL) presented on catalyst-ionomer interactions and AEMFC durability.

\section{Membrane-Focused Presentations}

Mark Pouy (ARPA-E) went through the targets that ARPA-E had established for AEMs (Topic 3 ) in the IONICS program. The presentation included background on the properties of interest and the rationale for choosing the specific properties and property targets. It included discussion of parallel targets for proton exchange membranes (PEM), which are at a much higher technology readiness level and have had significantly more effort placed into establishing property metrics. The IONICS metrics were put together with limited time and input from the technical community, and one of the goals of this workshop was to review and assess the metrics and suggest potential changes or expansion. Specific challenge areas highlighted to be addressed were that the IONICS targets included a single set of metrics for both electrolysis and fuel cell applications; they were membrane specific and didn't include device testing; they didn't have any direct mechanical testing; and they left room for inconsistencies in procedures between groups.

Mike Yandrasits $(3 \mathrm{M})$ reviewed membrane testing challenges and standardization. Perfluorosulfonic acid characterization was highlighted initially to demonstrate the challenges faced in membrane characterization regarding accurate quantification of water uptake and humidity. AEM characterization includes all the challenges associated with PEM characterization but has additional challenges with carbonation and in some cases chemical degradation of ionic groups. This presentation focused on efforts to develop consistent protocols and measurements of properties between different research groups highlighting ion exchange capacity (IEC) and conductivity. The following list is a summary of comments and recommendations from the presentation:

- Relevant tests and methods for AEMs are likely to be different than for PEMs.

- Many routine measurements are harder to do well than they appear.

- Accurate relative humidity (RH) measurements are critical for RH-dependent conductivity. 
- Conductivity measurements should specify conditions used for dimensional measurements (e.g., wet, dry).

- Ion exchange methods are especially important for iodide or other high affinity cations.

- $\quad$ RH cycle testing is both empirical and highly dependent on system design.

\section{Device-Focused Presentations}

Bill Mustain (University of South Carolina) focused on state-of-the-art performance and durability of alkaline membrane fuel cells. This presentation highlighted the advances made in recent years focusing on factors including increasing power density and durability, the use of platinum group metal (PGM)-free catalysts, and the impacts of carbonation on cell performance. The presentation highlighted the importance of electrode fabrication in these advances and made several recommendations, including:

- Transition from focusing exclusively on materials to a more balanced approach that targets integration and performance.

- Create opportunities to marry experimental and modeling groups to better understand electrode level and cell level dynamics.

- Develop a membrane metric for minimum water transport rate.

- Start to design systems specifically for AEMFCs (not adjusted PEM fuel cells [PEMFCs]).

Yu Seung Kim (LANL) focused on catalyst-ionomer interactions and AEMFC durability. In the area of catalyst-ionomer interactions the topics of cation adsorption and phenyl adsorption were highlighted as critical concerns supported by in situ and ex situ studies. Phenyl adsorption was noted to have impact on AEMFC anode performance, AEMFC cathode durability, and AEM electrolysis anode durability. Cation co-adsorption was noted to have impact on AEMFC anode performance and AEMFC anode durability. This presentation promoted the subjects of ionomer performance, low PGM performance, non PGM performance, electrode processing, and liquid electrolyte for further electrode performance discussion.

The main session presentations can be found here: https:/www.energy.gov/eere/fuelcells/2019anion-exchange-membrane-workshop. 


\section{Breakout Sessions}

Each of the breakout groups had approximately 10 to 20 attendees, and each had a facilitator to stimulate and guide discussions as well as a scribe to capture the discussions. Following each breakout session, a joint session was reconvened in which the facilitator of each breakout session presented the session's findings.

The following sections provide summaries from each breakout group for the morning and afternoon breakout sessions.

\section{Morning Session: Membrane Focus}

The morning breakout session focused on membranes with attendees split among two breakout groups on standardized protocols (one on $\mathrm{CO}_{2}$ and conductivity; another on degradation, IEC, and mechanical properties) and a third on membrane metrics and targets. There was overlap in discussion and content among these groups, and highlights captured from the specific breakout sessions are presented below.

\section{Breakout Session 1: Standardized Protocols-Conductivity and $\mathrm{CO}_{2}$}

Facilitator: Mike Hickner, Penn State University

The breakout session on conductivity and $\mathrm{CO}_{2}$ was arranged due to the critical importance of conductivity of these membranes under device operating conditions and the tremendous challenges of studying hydroxide-containing materials in the presence of (ambient) $\mathrm{CO}_{2}$. The bulleted lists below summarize the discussion in three topic areas: conductivity, membrane thickness, and standard methods.

Discussion on conductivity:

- Need for good method for through-plane conductivity discussed-interfacial resistance pitfalls. Need to measure as a function of thickness for through-plane.

- Pitfalls for both in-plane and through-plane measurements.

- New method emerging for $\mathrm{OH}^{-}$form in electrolysis mode before conductivity measurement. Need to protect membrane from degradation.

- $\quad$ DC and AC measurements needed, although AC measurements are working well.

- DC verification of conductivity can be done with area specific resistance (ASR) measurements in running cells.

- Bekktech for in-plane and MTS (Scribner Membrane Test System) identified for throughplane. $\mathrm{Pt} / \mathrm{Au}$ electrodes with polyetheretherketone or polytetrafluoroethylene cells works well.

- Need to interpret effects of supports carefully in in-plane vs. through-plane as membranes can be anisotropic.

- Have to measure wet thickness dimensions to get the right calculated conductivities-micrometer is good enough here. 
Discussion on membrane thickness:

- 10-80 micron, maybe down to 5 micron.

- Thin membranes with moderate conductivity will give reasonable ASR in cells.

- Need to think about conductivity measurements on ionomers and project to ASR in cells and then verify.

- Perhaps $10 \mathrm{mS} / \mathrm{cm}$ is an approximate lower limit for intrinsic conductivity.

Discussion on standard methods:

- What ion form? $\mathrm{Cl}^{-}, \mathrm{HCO}_{3}{ }^{-}$, and $\mathrm{OH}^{-}$identified as good baselines.

- More fundamental work on $\mathrm{F}^{-}$needed. Other anions not particularly helpful.

- Water uptake-soaking in a beaker and weighing is standard and easy to access. Good repeats needed. Fully dry membrane at end of test, not beginning. Water uptake in $\mathrm{Cl}^{-}$ form for dry sample seems to maintain stability.

- Water uptake as a function of $\mathrm{RH}$ is probably best done in $\mathrm{Cl}^{-}$and $\mathrm{HCO}_{3}^{-}$.

- $\mathrm{Cl}^{-}$and $\mathrm{HCO}_{3}{ }^{-}$identified as quick screening ions. $\mathrm{OH}^{-}$done right is more involved and difficult to verify.

- Likely need a glovebox for the best $\mathrm{OH}^{-}$work. Even purging with $\mathrm{N}_{2}$ can have some $\mathrm{CO}_{2}$ in it.

- Big difference in swelling for $\mathrm{Cl}^{-}$vs $\mathrm{OH}^{-}$; might change percolation pathways in membrane and influence conductivity—-beyond ion mobility effects.

- Some reasonable correlations between $\mathrm{Cl}^{-}, \mathrm{HCO}_{3}{ }^{-}$, and $\mathrm{OH}^{-}$conductivity measurements.

- Mohr (halide titration) best for IEC.

- Multiple measurements are needed to verify stability and ensure good error bars. Is the membrane changing over time?

- Measurements over the course of 1 hour can verify if membrane is changing or not with regard to water uptake/ $\mathrm{CO}_{2}$.

- Degassed water is critical for $\mathrm{OH}^{-}$.

- Temperatures between $30^{\circ} \mathrm{C}$ and $80^{\circ} \mathrm{C}$ are probably good enough.

- $50 \% \mathrm{RH}$ is a good lower bound for conductivity.

- Hysteresis is important to evaluate-one or two up and down cycles in temperature are good.

- Need a standard RH protocol. Maybe $80 \%$ RH, then increase, then decrease. Need to watch for degradation.

- The areas of conductivity, membrane thickness, and standard methods overlap with discussions in the other breakout groups during the morning session. Much of the discussion will be saved for commonality and overlap for the membrane metrics/targets 
breakout session. A few other topics of interest were also discussed without adequate time for more thorough investigation. These include how to measure morphology and tortuosity.

- How to control water volume fraction and hydration number (lambda) and compare different materials.

- Counterion condensation. Difficult to measure, difficult to know how changing ions influences the condensation.

- Lambda 7 seems to be critical for distinguishing samples.

- Perhaps a list of best equipment.

\section{Breakout Session 2: Standardized Protocols-Degradation, IEC, and Mechanical} Properties

Facilitator: Chulsung Bae, Rensselaer Polytechnic Institute

The breakout session on degradation, IEC, and mechanical properties was arranged to cover the critical issues not covered in the conductivity and $\mathrm{CO}_{2}$ breakout session. As AEMs are a new class of ion exchange membrane materials for electrochemical energy conversion technology and there is no standard commercial AEM yet, their membrane characterization protocols have not been established yet. In this breakout session, a group of researchers discussed how to practice best protocols in determining membrane properties that are related to water absorption and durability of AEMs: IEC, degradation by alkaline stability test, water absorption properties, and mechanical properties. Among the properties discussed, the establishment of appropriate mechanical properties for AEMs has been suggested as the most urgent area.

Before particular measurements are designed/decided, their relevance to applications should be considered. As AEMs can be used for different applications, setting multiple targets for different technologies is recommended. It is also recommended that AEM researchers evaluate their properties in a step-wise manner: crucial early diagnostic tests for screening of AEMs followed by more refined tests for later stages. For example, once an AEM shows promising data in $1^{\text {st }}$ round tests, it can be moved to $2^{\text {nd }}$ round and $3^{\text {rd }}$ round tests subsequently. A list of step-wise tests includes:

- $\quad 1^{\text {st }}$ round (baseline polymer characterization): mechanical stability (see below for details), water uptake and swelling ratio, IEC, alkaline stability at $1 \mathrm{M} \mathrm{KOH} / 80^{\circ} \mathrm{C}$

- $\quad 2^{\text {nd }}$ round: electrochemical stability tests that mimic the electrochemical cell conditions (for fuel cell and electrolyzer), RH cycling/RH cycling with mechanical stability (for fuel cell), water permeability (for fuel cell and electrolyzer)

- $\quad 3^{\text {rd }}$ round: pressure cycling test (for electrolyzer), gas crossover (for fuel cell and electrolyzer).

\section{Mechanical Stability}

Mechanical stability of AEMs is critical for achieving durable operation of AEM-based electrochemical devices. As AEMs operate under hydrated conditions with varying hydration levels depending on applications, mechanical properties of AEMs should be evaluated with 
consideration of application. For example, the mechanical properties after RH cycling of AEMs may be important for fuel cells but are unlikely to be important in electrolyzer applications where continuous liquid water equilibration would be anticipated. Thus, establishment of application-specific mechanical property test conditions can be considered, for example: (1) stress-strain measurement at a specific temperature and RH for fuel cell applications; and (2) stress-strain measurement after soaking a membrane in liquid water at specified temperature for electrolyzer applications (details to be determined).

Swelling properties under various conditions are also important. Under electrochemical cell conditions, AEMs are subject to stress and swelling by water uptake, pushing the membrane to expand to all (x-, y-, z-) directions. It is important to connect swelling behavior under a hydrated condition with dimensional stability. Furthermore, water uptake and mechanical properties of AEMs are heavily dependent on what anion form is used in the measurement. As typical AEMbased devices operate under alkaline conditions in hydroxide ion form, it is desirable to evaluate the mechanical properties in hydroxide ion form. However, unlike water uptake measurements in hydroxide ion form, which can be completed quickly, mechanical property measurements would need more time to equilibrate the membrane sample with a specific instrument condition. Therefore, due to the difficulty of preserving an AEM in hydroxide ion form and its potential contamination with atmospheric $\mathrm{CO}_{2}$, most researchers tend to evaluate the mechanical property of AEMs in non-hydroxide ion form (mostly halide ions). The breakout discussion focused on how to measure mechanical properties (i.e., protocols) and how to correlate the measured properties with the durability at the device level.

Regarding particular measurements of mechanical properties, measurement of stress-strain behavior is the most commonly practiced method. Although specific conditions (temperature and RH level) need to be defined and justified for various applications, the following is a list of discussed and generally accepted opinions regarding mechanical stability:

1. In the stress-strain curve, a certain minimum level of stress energy (e.g., $>10 \mathrm{MPa}$ ) is required. Once an AEM achieves the level of sufficient stress energy, elastic behavior (strain) is more important than stress. For example, Nafion's elongation at break is $300 \%$. Modulus (ratio of stress/strain) is not as important as a mechanical property metric in AEMs.

2. When evaluating the elastic property of AEMs, elongation at break as well as maximum recoverable elastic strength (yield point) should be considered. Most AEMs behave like plastic, not elastomer; thus, the membrane cannot recover its original mechanical property (both stress and strain) beyond the yield point. For example, the membrane's stress and strain become irreversible after a certain number of RH cycles. In this regard, cyclic mechanical property measurements of stress and strain (even in a few cycles) might give more information about the permanent deformation of AEMs.

3. Test specimen shape for mechanical property test: Although a dog bone shape is commonly practiced for ASTM International measurements of strain and stress of polymer materials, this shape is not suitable for thin films. It has been suggested that AEM researchers use a different shape, such as a rectangular ASTM standard. 


\section{Water Uptake and Swelling Ratio}

Although water uptake is important to correlate an AEM's interaction with water, the measurement protocol should be dependent on the application of the AEM. For fuel cell applications, water uptake measurements should be done at different RHs at a specified temperature. For electrolyzer applications, water uptake measurements should be done after submerging the membrane in water for a certain time at a specified temperature (e.g., $2 \mathrm{~h}$ at $50^{\circ} \mathrm{C}$ ). Swelling ratios in $\mathrm{x}-, \mathrm{y}-$, and $\mathrm{z}$-directions need to be evaluated. Water uptake and swelling ratio measurements are included as $1^{\text {st }}$ round measurements for AEMs, but researchers may not be sure whether their AEMs are more appropriate for fuel cell vs. electrolyzer applications until a later stage, so it is recommended that water uptake and swelling ratio measurements be conducted under both conditions.

\section{Ion Exchange Capacity}

To better understand the interaction of AEMs with water (e.g., water uptake, lambda), accurate measurement of IEC is critical. In general, measurement of IEC for an AEM by Mohr's titration method is straightforward and easy to follow as long as a sufficient amount (>100 mg) of sample is available (the Mohr's titration method is based on the amounts of released halide ion from AEM by titrating with $\mathrm{AgNO}_{3}$ ). A notable discrepancy in Mohr's titration IEC has been observed for AEMs with iodide anion form because iodide ion is hard to remove by simple ion exchange reaction conditions. Thus, if AEMs are prepared by quaternization with methyl iodide, researchers should be careful in the measurement of IEC by Mohr's titration and should confirm the complete removal of iodide ion, which can be detected by inductively coupled plasma mass spectrometry. It has been suggested that iodide should be substituted with other halide forms (e.g., chloride ion) first before IEC is measured by Mohr's titration method.

If an AEM is soluble in a deuterated solvent, IEC measurement by nuclear magnetic resonance (NMR) spectroscopy is also advisable as it gives reliable IEC values and requires much less sample (10 mg). It should be noted that the IEC measurement by NMR spectroscopy should employ AEMs in non-hydroxide ion form (e.g., halide or bicarbonate forms) as AEMs in hydroxide ion form can experience accelerated degradation during dissolution of the AEM in a non-aqueous NMR solvent such as DMSO-d6.

\section{AEM Stability Test}

Currently, the most commonly practiced alkaline stability test is conducted by immersing membrane samples into $1 \mathrm{M} \mathrm{KOH} / \mathrm{NaOH}$ at $80^{\circ} \mathrm{C}$ for a certain period of time (e.g., $1,000 \mathrm{~h}$ ) and measuring changes in IEC and ion conductivity. Although numerous recent AEMs have been reported to pass this basic alkaline chemical stability test, none of them have shown good stability in electrochemical cells over $1,000 \mathrm{~h}$ (fuel cell and electrolyzer). Thus, it is strongly recommended to establish an electrochemical oxidative stability/stress test that should mimic real electrochemical cell conditions in the $2^{\text {nd }}$ round in addition to the basic alkaline stability test using $1 \mathrm{M} \mathrm{KOH} / \mathrm{NaOH}$ in the $1^{\text {st }}$ round.

\section{Relative Humidity Cycling Test}

Although this test is specific only for fuel cell applications, and a few researchers have expressed reservations about the relevance of this test in AEMs, the consensus is that it should be included as a $2^{\text {nd }}$ round test. Mechanical properties after RH cycling test results should be analyzed in 
coupling with ion conductivity. The test method follows General Motors' empirical protocol. As AEM development is in an early stage, AEMs may not need to surpass 20,000 cycles, but this test will offer valuable evaluation information for fuel cell application.

\section{Water Permeability, Pressure Cycling Test, and Gas Crossover}

The areas of water permeability, pressure cycling, and gas crossover were also noted as being important for AEMs, but discussions on these topics were limited due to time constraints. Brief discussions on these topics included water permeability as a new property to be measured in the $2^{\text {nd }}$ round of testing for both fuel cell and electrolyzer applications. The pressure cycling test was suggested to be done by measuring nitrogen permeation rate and should be only considered when a membrane is ready for use in an electrolyzer device. The gas crossover was seen as a broader test than pressure cycling; it could be measured in cells and also should be considered when membranes are ready for device use. This test was thought to be relevant for both electrolyzers and fuel cells.

\section{Breakout Session 3: Membrane Metrics and Targets}

Facilitator: Mike Yandrasits, 3M

This breakout session centered on modifications to the AEM targets proposed by the ARPA-E IONICS program. The proposed targets and suggested changes are shown in Table 1. There was general agreement that these were adequate for membrane qualification. Some expressed the opinion that there should be staged, or gated, targets to help development without overly restricting choices early in AEM development. Second-stage targets would be geared toward MEA measurements whereas first-stage targets could mainly be ex situ membrane testing.

The membrane chemical stability test of $1,000 \mathrm{~h}$ in $\mathrm{pH} \geq 14$ solution is a reasonable screening test and not too aggressive. Participants agreed that AEMs should demonstrate $<5 \%$ change in ASR and IEC, as the originally proposed $2 \%$ change was suggested to be smaller than the measurement error. There was some discussion of whether $1,000 \mathrm{~h}$ was adequate, and if there was a more aggressive test to reduce the testing time. Ammonium cation-based AEM testing has been done at elevated temperature, decreased RH, and varying hydroxide ion concentrations, which indicated that harsher conditions changed the degradation mode from $\beta$-elimination to nucleophilic substitution $\left(\mathrm{S}_{\mathrm{N}} 2\right)$. Furthermore, at higher hydroxide concentrations, crosslinking can occur (usually seen as a sharp initial decrease in IEC). At low temperature, $\mathrm{OH}^{-}$ion concentration does not have much impact on the degradation rate. Some indicated a preference for specifying hydroxide concentration (e.g., $4 \mathrm{M} \mathrm{NaOH}$ or $\mathrm{KOH}$ ) rather than a $\mathrm{pH} 14$ solution, notwithstanding the concerns about crosslinking, whereas others indicated high $\mathrm{OH}^{-}$content was relevant for electrolyzer applications. The group generally agreed that alkaline stability testing should be used as an early screening tool for new polymers; thus, degradation of mechanical properties need not be included in this metric.

The ARPA-E target specifying a minimum component area for which the property values were achieved was discussed. The ability to make a $100 \mathrm{~cm}^{2}$ membrane is an indication of the ability to scale up ionomer synthesis for a particular chemistry, giving some measure of how practical its manufacture will be; however, the group suggested deprioritizing or deleting this target because of the constraint it places on early polymer synthesis, which may be overcome during further process development. 
An important element of the discussion of the membrane ASR target was whether ASR or conductivity would be the most appropriate metric. Because ASR is typically calculated from an ex situ conductivity measurement (or from MEA measurement), conductivity was proposed to be the more appropriate metric for early membrane qualification. The group did not arrive at an optimal target for conductivity, which would have required assuming a certain membrane thickness to derive conductivity from the ASR target.

The ARPA-E target proposes ASR measurement at $80^{\circ} \mathrm{C}$, but measurements at $40^{\circ} \mathrm{C}$ and $80^{\circ} \mathrm{C}$ were deemed more appropriate. Currently, most groups are performing ASR measurements at $40^{\circ} \mathrm{C}$, but this low temperature does not reflect realistic conditions for many applications due to the difficulty in meeting power density and efficiency requirements while rejecting sufficient heat; thus, measurement at $80^{\circ} \mathrm{C}$ better approximates real-world operation. The lowertemperature condition is also relevant to flow batteries and other applications. These membranes should be water equilibrated, and a steady-state measurement should be made.

The need to set a realistic ASR target was emphasized. Some expressed the opinion that the AEM ASR target should be equivalent to the PEM ASR target of $0.02 \Omega-\mathrm{cm}^{2}$, per the FCTO Multi-Year Research, Development, and Demonstration Plan; however, others stated it may be acceptable to have higher ASR for AEMs because there are other benefits that might make trading AEMs for PEMs worthwhile.

The group agreed that eliminating the target for ASR testing in the presence of $\mathrm{CO}_{2}$ was not necessary, as most expected applications would use $\mathrm{CO}_{2}$-free air (e.g., by scrubbing intake air). Measurement should be taken at $80-90 \% \mathrm{RH}$ instead of $50 \% \mathrm{RH}$ in order to slow degradation and prevent drift. Despite the difficulty in ex situ testing without exposure to $\mathrm{CO}_{2}$, the need for careful testing was emphasized, as exposure to air can lead to an $80 \%$ decrease in conductivity. Although it was not the purview of this session to set application-specific targets, the disparate conditions in which fuel cells, electrolyzers, and flow cells operate was noted. For example, high-RH conditions are more relevant for electrolyzers, and flow batteries can tolerate higher ASR due to lower operating current densities.

In contrast to PEM systems, the humidity cycle/mechanical durability target was not seen as a useful target for AEMs. The requirements for water in an alkaline system make it highly unlikely an AEM would see the drastic RH changes a PEM membrane experiences. It was agreed that this test can be eliminated. Other mechanical tests are expected to be important. This conclusion is in contrast with Breakout Session 2, in which participants suggested this was a meaningful test, although even Breakout Session 2 debated the topic. This reflects the uncertainty of the ability or need to operate these devices under broad ranges of $\mathrm{RH}$.

The electronic ASR target of 1,000 $\Omega-\mathrm{cm}^{2}$, equivalent to the PEM target (FCTO 2017), was accepted without any changes. Similarly, the humidity stability factor test was considered to be a useful indicator and should be kept as written. Because the proposed value of $>5$ includes a safety factor, this should not be a strict pass/fail metric. The cost target was also found to be relevant and the target cost deemed appropriate.

The membrane swelling target should specify that this is for the hydroxide form of the membrane, in water, and that it should be measured as the linear swell in the X-Y plane. A value 
of $50 \%$ swell would not be acceptable in electrolyzers; however, some latitude should be given for supported membranes, which are being adopted more widely and mitigate some swelling, potentially bringing the value below an acceptable threshold.

The breakout participants believed the pressure differential test was not necessary for fuel cell and flow battery applications. The ability to withstand a pressure differential is very important for electrolyzer applications; however, there was not consensus on how this test should be performed. Furthermore, the need for the membrane to withstand pressure differential is not clear, as in an MEA, the gas diffusion layer supplies most of the rigidity. A burst test, such as developed by General Motors and Virginia Tech, might be useful (Yongqiang et al. 2009; Dillard et al. 2009; Grohs et al. 2010). The complication to this approach is that a burst test provides ultimate elongation whereas the target would dictate elongation at a specific pressure. Additional input is required from the electrolyzer industry regarding recommended parameters for a burst test or suggestions for other relevant tests and targets.

The $\mathrm{H}_{2}$ gas crossover target was considered very important. The analogous PEM target (converted from molar flux to current) to that proposed by ARPA-E is $<8 \mathrm{~mA} / \mathrm{cm}^{2}$ for a $30-\mathrm{cm}^{2}$ cell. The PEM target set by the FCTO is $<2 \mathrm{~mA} / \mathrm{cm}^{2}$. Participants suggested the $\mathrm{H}_{2}$ crossover target be made more challenging by decreasing it to $<5 \mathrm{~mA} / \mathrm{cm}^{2}$. As for the $\mathrm{O}_{2}$ crossover target, the measurement requires special equipment and presents a safety risk. Although $\mathrm{N}_{2}$ use as a surrogate is common practice, $\mathrm{H}_{2}$ crossover in AEMs should be higher than $\mathrm{O}_{2}$ crossover because $\mathrm{O}_{2}$ is not as soluble in typical AEM membranes. Therefore, AEMs that meet the $\mathrm{H}_{2}$ crossover target should also surpass the $\mathrm{O}_{2}$ crossover target, and $\mathrm{O}_{2}$ crossover testing would be superfluous.

Two additional targets were proposed. Due to the paramount importance of water management in AEMs, a water transport/flux target would be very useful in membrane qualification. An initial membrane water transport rate target of $4 \mu \mathrm{mol} / \mathrm{cm}^{2}$-s would account for the need for diffusion of water from the anode to the cathode in fuel cell operation. An ionic permeability target relevant to flow batteries was also proposed. Choosing a metric is difficult due to the variety of chemistries being investigated, but a target limiting $\mathrm{V}^{4+}\left(\mathrm{VO}^{2+}\right)$ transport is a logical starting point because it is a stable ion and may provide a reasonable estimate of the transport properties of other ionic species. A target of $<7 \times 10^{-8} \mathrm{~cm}^{2} / \mathrm{s}$ was suggested. 
Table 1. Suggested Changes to ARPA-E IONICS AEM Targets (ARPA-E 2016)

\begin{tabular}{|c|c|c|}
\hline Metric & ARPA-E Targets & Suggested Change \\
\hline $\begin{array}{l}\text { Membrane chemical } \\
\text { stability (at } \geq 80^{\circ} \mathrm{C} \\
\text { immersed in a } \mathrm{pH} \geq 14 \\
\text { solution) }\end{array}$ & $\begin{array}{l}\geq 1,000 \text { h with } \leq 2 \% \\
\text { loss in IEC, ionic } \\
\text { ASR, spectroscopic } \\
\text { measures of } \\
\text { membrane state, and } \\
\text { mechanical } \\
\text { properties }\end{array}$ & $\begin{array}{l}\geq 1,000 \mathrm{~h} \text { with } \leq 5 \% \text { loss in IEC and conductivity; } \\
\text { should include spectroscopic characterization }\end{array}$ \\
\hline $\begin{array}{l}\text { Component area over } \\
\text { which property values } \\
\text { are achieved to within } \\
\geq 90 \% \text { uniformity }\end{array}$ & $\geq 100 \mathrm{~cm}^{2}$ & Delete this target or decrease priority \\
\hline $\begin{array}{l}\text { lonic ASR (hydroxide } \\
\text { form, } 80^{\circ} \mathrm{C} \text {, liquid } \\
\text { equilibrated) }\end{array}$ & $\leq 0.04 \Omega-\mathrm{cm}^{2}$ & $\begin{array}{l}\text { No change to } 80^{\circ} \mathrm{C} \text { target } \\
\text { Add a target at } 40^{\circ} \mathrm{C}: 0.04 \Omega-\mathrm{cm}^{2}\end{array}$ \\
\hline $\begin{array}{l}\text { lonic } \mathrm{ASR}\left(80^{\circ} \mathrm{C}, \leq 50 \%\right. \\
\mathrm{RH}, \text { under air exposure, } \\
\text { [i.e., in presence of } 400 \\
\left.\left.\text { ppm } \mathrm{CO}_{2}\right]\right)\end{array}$ & $\leq 0.08 \Omega-\mathrm{cm}^{2}$ & $\begin{array}{l}\text { Change to a measurement at } 80 \% \mathrm{RH} \text { under } \mathrm{CO}_{2-} \\
\text { free air exposure; keep target at } \leq 0.08 \Omega-\mathrm{cm}^{2}\end{array}$ \\
\hline $\begin{array}{l}\text { Mechanical durability } \\
\text { during humidity cycling }\end{array}$ & $\geq 20,000 \mathrm{RH}$ cycles & Delete this target \\
\hline Electronic ASR & $\geq 1,000 \Omega-\mathrm{cm}^{2}$ & No change proposed \\
\hline Humidity stability factor & $>5$ & No change proposed \\
\hline $\begin{array}{l}\text { Swelling in liquid water } \\
\text { at } 25^{\circ} \mathrm{C}\end{array}$ & $<50 \%$ & $\begin{array}{l}\text { To be measured as linear swell in } \mathrm{X}-\mathrm{Y} \text { plane in } \\
\text { water, membrane in } \mathrm{OH}^{-} \text {form }\end{array}$ \\
\hline Pressure differential & $\geq 1$ bar & $\begin{array}{l}\text { Delete for fuel cell and flow battery applications; } \\
\text { electrolyzer industry input on burst test or other } \\
\text { relevant test and metrics needed }\end{array}$ \\
\hline $\begin{array}{l}\mathrm{H}_{2} \text { crossover and } \mathrm{O}_{2} \\
\text { crossover }\end{array}$ & $\leq 25 \mathrm{nmol} / \mathrm{cm}^{2}-\mathrm{s}$ & $\begin{array}{l}\text { Change to }<5 \mathrm{~mA} / \mathrm{cm}^{2} \text { for } \mathrm{H}_{2} \text { crossover, eliminate } \\
\mathrm{O}_{2} \text { crossover target }\end{array}$ \\
\hline $\begin{array}{l}\text { Cost for membrane that } \\
\text { can be practically } \\
\text { integrated in a device }\end{array}$ & $\leq 20 \$ / \mathrm{m}^{2}$ & No change proposed \\
\hline $\mathrm{H}_{2} \mathrm{O}$ transport & --- & $\begin{array}{l}\text { New target proposed for water transport: }>4 \\
\mu \mathrm{mol} / \mathrm{cm}^{2}-\mathrm{s}\end{array}$ \\
\hline Ionic permeability & --- & $\begin{array}{l}\text { New target proposed for flow batteries to limit } \\
\text { permeability of other ions: }<7 \times 10^{-8} \mathrm{~cm}^{2} / \mathrm{s}\end{array}$ \\
\hline
\end{tabular}




\section{Afternoon Session: Device Focus}

The afternoon breakout sessions focused on issues associated with AEM-based electrochemical devices. While progress in AEMs over the past few years has been substantial, ultimately these membrane advances are only valuable if they provide improved device performance. Devices, as compared to membranes, have additional challenges associated with electrode performance and water and $\mathrm{CO}_{2}$ management. The three breakout session topics-electrode performance; water and $\mathrm{CO}_{2}$ management; and device performance and durability milestones, metrics, and targets -were chosen to address these device issues while also looking to explore relevant device targets. While there is a concern for all AEM-based electrochemical devices, the discussion in the breakout sessions was heavily weighted toward fuel cells due to the amount of effort in the area, although electrolyzers also were discussed.

\section{Breakout Session 1: Electrode Performance}

Facilitator: Yu Seung Kim, Los Alamos National Laboratory

Perhaps some of the biggest improvements seen in AEM-based devices have come from improved electrode performance. This is most notable in fuel cells, which have seen most of the research and development (R\&D) effort. AEM fuel cells have more than doubled peak power density and shown great improvements in durability (up to 1,000 hours), though much of the degradation still seen is likely due to the electrode. The electrode layer has concerns with water management, mass transfer, and catalyst-ionomer interactions that need to be better understood and further optimized to reach performance and durability levels required for commercial competitiveness.

It was understood by the breakout session participants that to be a viable technology option, AEMFCs and AEM water electrolyzers should be competitive with PEM-based technologies, which can be achieved by (a) higher performances for specific applications, (b) prolonged durability, and (c) being economically preferable (cheaper than existing state-of-the-art PEM devices). The discussion started with molecular design perspectives of ionomers for AEM device electrodes and moved to the natural advantage of AEMFCs by using PGM-free catalysts for the oxygen reduction reaction (ORR) and hydrogen oxidation reaction (HOR). Additionally, the possibility of using a low-PGM-loaded HOR electrode was discussed, taking into account the total PGM loading should be $<0.125 \mathrm{mg} / \mathrm{cm}^{2}$. Finally, R\&D needs for AEM water electrolyzers were briefly discussed.

\section{Ionomeric Binder for Fuel Cells and Electrolyzers}

Recent progress on AEMFC performance is mainly due to the advanced ionomers used at the electrodes. On top of the alkaline stability of the ionomer, the ionomer used at the electrodes should not interfere with the catalyst activity. It seems to be a hard nut to crack to develop new ionomers that would not adsorb to the catalyst surface. Also, when an ionomer does not have suitable transport properties, the membrane may experience harsher conditions during operation (i.e., dehydration), which accelerates membrane degradation. A specific cationic functional group may be required for different purposes (membrane, anode ionomer, and cathode ionomer). In addition to developing various ionomers for separate electrodes, a different fabrication method would be more useful for each purpose. Ionomers with polyolefin backbone may be free from 
backbone adsorption issues, but they may cause thermal stability issues and exacerbate water management.

\section{PGM-Free ORR Catalysts}

Recent progress in the development of PGM-free ORR catalysts (under DOE's ElectroCat consortium effort in the United States and overall internationally) brought the M-N-C type of materials to quite a high technology readiness level. Many developed catalysts tested in AEMFCs demonstrated performances either similar to or higher than $\mathrm{Pt} / \mathrm{C}$ (tested with the same AEM materials, MEAs prepared by the same method, and the same test conditions). The substantial development of increasing AEMFC performance using oxides and silver as PGM-free ORR catalysts was reported.

Based on the discussion, it was summarized that among three different potential PGM-free ORR classes (M-N-C, transition metal oxides, and silver-based materials), the M-N-C class is most mature. However, taking into account that their performance should be demonstrated in fuel cell tests, it was proposed that significant effort should be invested in the integration of these materials in the catalyst layer. Later work may require the development of new types of ionomers allowing the production of well-dispersed inks, methods of dispersion, and electrode fabrication. The potential risks associated with poor mass transfer in $\mathrm{M}-\mathrm{N}-\mathrm{C}$ cathodic layers may need to be further investigated.

\section{PGM-Based ORR Catalysts}

It was decided that research efforts should not focus on PGM catalysts for the cathode side of AEMFCs at this moment.

\section{PGM-Free HOR Catalysts}

A project previously funded by DOE FCTO on development of PGM-free HOR catalysts has demonstrated the feasibility of using Ni-based materials for anodes in AEMFCs. However, it was noted that significant effort is required in this field to bring this material performance- and durability-wise to the level of PGM catalysts. The main issues associated with N-based materials were an intrinsically low mass activity, the tendency to oxidize and lose HOR activity, and specific detrimental interaction with AEM ionomers. The proposed mitigation strategies included using higher loadings on Ni-based HOR catalysts, making intermetallics and alloys with higher resistivity to oxidation, and developing different ionomers without poisoning effects. It was estimated that the development effort for PGM-free HOR materials requires more resources compared to ORR materials, while still promising high payoff if successful.

\section{PGM-Based HOR Catalysts}

The possibility of developing PGM catalysts with low loading $\left(<0.1 \mathrm{mg} / \mathrm{cm}^{2}\right)$ on the anode was discussed. It was noted that this direction is a challenging task for both catalyst and ionomer developers as the catalyst loading decreases. As it was reported, several classes of ionomers have a significant poisoning effect on PGM catalysts, decreasing HOR activity. Based on previous data, the most probable specific combinations of PGM+ionomer should be screened to obtain the highest performance and durability. 


\section{Electrode Fabrication for High Performance}

The development of the new ionomer is good, but the ionomer evaluation is often time consuming and costly. A standard screening method may need to be developed. Measuring ionomer performance without MEA fabrication is difficult, but some screening can be done by (1) DFT calculation and (2) a small analog study using a model compound using rotating disk electrode. HOR/hydrogen evolution reaction and oxygen evolution reaction/ORR activity of catalysts need to be tested separately. Testing with Pt would be irrelevant because of the need to move to low- or non-PGM catalysts at some point. Due to the different loading requirements of AEMFCs, limiting the total PGM loading for the MEAs would be a better idea. Ionomer interaction on different metal catalysts might be different. Therefore, ionomer-catalyst pairing is essential and an area for investigation.

\section{Prioritized R\&D Needs for AEMFCs}

Due to the potential for significant improvements, the development of ionomers and advanced HOR catalysts may be the highest AEMFC R\&D priority. Ionomers need to be developed based on the different reaction requirements of AEM-based devices. The main focus of HOR catalyst R\&D should be on the development of PGM-free catalysts that are durable and have stable performance exceeding that of PGM-based HOR catalysts. Additionally, low loading PGMbased HOR catalyst development could be appropriate. At a certain point in time, the AEMFC performance and cost of MEAs employing non-PGM HOR catalyst and low-loading PGM catalyst $\left(<0.1 \mathrm{mg}_{\mathrm{PGM}} / \mathrm{cm}^{2}\right)$ needs to be compared.

While significant opportunities exist for improvement on the anode, significant R\&D on the cathode also should be performed. AEMFC cathode catalysts have not been investigated as thoroughly as equivalent PEMFC catalysts have, so substantial opportunities for improvement still exist. Because viable PGM-free cathode catalysts already have been demonstrated, all future AEMFC cathode R\&D should focus on PGM-free materials. The most promising materials at this point are M-N-C catalysts, similar to those under investigation for PEMFCs, and hybrid materials of $\mathrm{M}-\mathrm{N}-\mathrm{C}$ with transition metal oxides or silver should be evaluated.

\section{R\&D Needs for AEM Electrolyzers}

This topic was discussed briefly and summarized below:

- For AEM electrolyzers, exceptionally stable ionomers would be required as higher potential at the anode may oxidize the AEM and ionomers.

- Performance metrics to measure the ionomer performance should be set up.

- Mass transport/water flux through membranes may be a significant issue. Depending on different catalysts, different oxidized moieties can be generated.

- OER activity is where the problem of lower performance compared to that of PEM-based electrolyzers occurs.

- The components should be modified or developed just for electrolyzers; most of them are optimized for fuel cells, not for electrolyzers.

- There was some discussion on using pure water vs. adding some electrolytes: 
- Potassium carbonate affects electrode performance.

- Adding alkaline liquid electrolyte through the cathode seems to be a bad idea.

\section{Breakout Session 2: Water and $\mathrm{CO}_{2}$ Management}

\section{Facilitator: Adam Weber, Lawrence Berkeley National Laboratory}

AEM-based devices have water and $\mathrm{CO}_{2}$ management issues that go beyond concerns of PEMbased devices. These issues can be largely mitigated in electrolysis operation where avoiding ambient $\mathrm{CO}_{2}$ and operating in a flooded, liquid water state reduce concern. However, fuel cell operation is highly impacted by these issues.

$\mathrm{CO}_{2}$ exposure or carbonate formation (even at atmospheric concentrations) has been a major issue for fuel cell operation. The breakout group discussion saw this as a critically limiting concern for fuel cell operation. While fuel cells have demonstrated the ability to self-purge at low cell operating voltage (high current density), the performance impact under standard operating conditions tends to be large (above $100 \mathrm{mV}$ ). This level is too high for competitive device performance under many applications. Recent modeling and experimental work in this area point to the only solution being avoiding exposure to everything but the lowest levels of $\mathrm{CO}_{2}$. Several breakout session participants suggested $5 \mathrm{ppm}$ might be acceptable, but the ultimate exposure level and operating strategy has yet to be determined. Broad agreement was achieved that ambient levels were too high, and that the $\mathrm{CO}_{2}$ level had to be much lower or, ideally, eliminated. Possible solutions include working off of $\mathrm{CO}_{2}$-free gases (such as $\mathrm{O}_{2}$ in a stationary/reversible system) or scrubbing $\mathrm{CO}_{2}$ from the air (something that would be easier to achieve in a stationary application but might also be possible in an on-board application). The relatively low ( $\sim 400 \mathrm{ppm})$ level of $\mathrm{CO}_{2}$ in the atmosphere means that absorbent-based systems that either use the waste heat of the fuel cell, electricity from the fuel cell, or hydrogen as the energetic driving force are possible.

Water management is particularly complicated for AEMFCs, much more so than for PEM-based devices, as water is produced at the anode for AEMFCs and consumed at the cathode. This adds the complication that water builds up at the anode, where gas flow rates are lower, and the water balance is much more difficult to maintain, as the cathode largely relies on back diffusion of water from the anode, but higher fluxes are required for the same current density relative to PEMFCs. Much of the performance improvements obtained in the past few years have been the direct result of improved water management in the AEM MEA. This situation is further complicated by the loss of performance and durability of AEMs when they dehydrate. The operating window between flooding and detrimental dehydration in these systems is narrower than that of PEM systems, and this may limit the ability of these systems to respond effectively to a wide range of operating conditions-for example, the ability to operate under both hot/dry and cold/wet conditions (often discussed in terms of robustness). High performance is achievable in these devices, as is reasonable durability under static conditions, but advances are required if more dynamic operating conditions and further durability improvements are to be achieved.

The breakout session discussed areas of concern for $\mathrm{CO}_{2}$ and water management in terms of gaps and research needs, and a summary is presented in the bulleted lists below. 
- Detailed understanding of physical phenomena

- Do we have conditioning protocols for fuel cells and electrolyzers?

- Understanding cell components and needs

- Should the cell design and operation dictate what we need to do in terms of material development?

- How should we operate AEMFCs from a system point of view that may be different than PEMFC - for example, temperature, $\mathrm{RH}$, transients?

- How do AEMFCs operate under the full range of expected conditions?

- How can we bring more water to the cathode at all places in the cell?

- What does carbonate do for electrolyzers?

- In electrolyzers do we worry about dry out and bubble management?

\section{Research Needs}

- Diagnostics:

○ Water transport measurements

- Water balance measurements

○ High resolution neutron imaging

○ Thermal conductivity of membranes

○ Segmented cell

- Reference electrode

○ Limiting current

- Electrochemically active surface area

O Oxygen gain and delta $\mathrm{V}$ analysis

○ Durability

- Accelerated stress tests

- Need more analysis of system failure.

- Materials:

- Need water management strategy that allows for broader range of temperatures and humidity

○ Electrolyzer: different coatings for $\mathrm{Ti}$

- Need to bring more water to cathode so need to change gas diffusion layer nature and microporous layer perhaps

- Can we bring water to the cathode in different ways? 
- Flow fields and channels

○ Fabrication

- Catalyst coated membrane vs. gas diffusion electrode.

- Recoverable vs. irrecoverable durability

○ Synergistic high-fidelity modeling and experiments.

The breakout group also discussed areas of interest specific to AEM electrolyzers and fuel cells related to $\mathrm{CO}_{2}$ and water management. Again, key questions and issues are highlighted in the bulleted lists below.

\section{Electrolyzers}

- Do we need carbonate?

- What are water management issues?

- Porous layers

- Mechanical and assembly

- Redesign cells?

- Bubble management?

- Issues with dry out and liquid balance as well.

Fuel Cells

- Humidification comes from the anode

- Low PGM and non PGM?

- Robustness
○ Humidification
○ Flowrates

- Electrode fabrication: high volumes, reproducible, scalable

- Conditioning protocols?

- Mechanical

- Water transport metric

- Operate differently?

○ Where can out compete?

○ Operating windows.

Breakout Session 3: Device Performance and Durability Milestones, Metrics, and Targets

Facilitator: Bill Mustain, University of South Carolina 
This breakout group discussed milestones, metrics, and targets for the AEMFC MEA. The general opinion was that the milestones should be set so AEMFCs start rivaling PEMFCs, and the ultimate targets should be set to show AEMFC advantages over PEMFC. The main potential advantage being cost, targets should be set with significantly lower PGM loading. A total loading of $0.05 \mathrm{mg} \mathrm{PGM}_{\mathrm{PG}} / \mathrm{cm}^{2}$ was proposed, while others indicated AEMFCs had been sold on the promise of PGM-free operation. It was stated that HOR is slightly worse in alkaline conditions than in the acid, and that a total loading (all on the anode?) of $0.05 \mathrm{mg}$ PGM $/ \mathrm{cm}^{2}$ would be reasonable and result in total PGM loading less than that for PEM or for a catalytic converter. There was some discussion about PGM recycling, and it was mentioned that at some lower loading, recycling becomes more expensive than the cost of the Pt recovered. It was not clear what that loading would be, but it was thought that $0.1 \mathrm{mg} \mathrm{PGM} / \mathrm{cm}^{2}$ would be above that threshold. For PGM-free MEAs, recycling is less of an issue, as the catalysts are expected to be much less resourcelimited. It was decided that near-term milestones and targets for PGM loading should approach that for current PEM targets, with the ultimate goal of having PGM-free systems. Even though AEMFC stack costs may be lower, PEMFCs can operate without external humidification. Current AEMFCs need humidification, but it is not clear whether AEMFC system designs can also be realized without external humidification. It also appears that $A E M F C$ s will require $\mathrm{CO}_{2}$ mitigation strategies. Thus, it is not presently clear how system costs compare.

There was a discussion of whether the cell areal and stack volumetric power density targets for AEMFCs need to match that for PEMFCs or if we could accept lower power density. Going to PGM-free catalysts will decrease cost, but their lower activity will likely lead to lower areal power densities and require thicker catalyst layers, likely leading to reduced volumetric power densities compared to the best PGM-containing embodiments. However, it was pointed out that even if catalyst costs are less, you still have limited space to fit the stack in the car, and PEM power density targets were initially derived from the space requirements. Targets should not be set below that required for space limitations in light-duty vehicle applications. In addition, the power density should be determined at the rated power, taking into consideration heat rejection and $\mathrm{Q} / \Delta \mathrm{T}$ targets rather than using peak power density. Heat rejection is an issue for light-duty vehicle applications and likely will be even more of an issue for emerging heavy-duty applications. $\mathrm{Q} / \Delta \mathrm{T}$ is dependent on the operating temperature, and most alkaline membranes haven't demonstrated durability at temperatures higher than $80^{\circ} \mathrm{C}$, while the $\mathrm{Q} / \Delta \mathrm{T}$ targets for PEMFCs would indicate power density be determined at $0.76 \mathrm{~V}$. The breakout group took a position that near-term targets and milestones should be $1 \mathrm{~W} / \mathrm{cm}^{2}$ at $0.65 \mathrm{~V}$ at $80^{\circ} \mathrm{C}$, realizing this does not meet the $\mathrm{Q} / \Delta \mathrm{T}$ target-current AEMs do not have the required durability at higher temperature, but it is expected that future membranes will, and trying to meet power density at $0.76 \mathrm{~V}$ is not currently realistic. The discussions about heat rejection and the $\mathrm{Q} / \Delta \mathrm{T}$ target made it clear that research needs to address increasing AEM operating temperatures and should target maximum operating temperatures of at least $95^{\circ} \mathrm{C}$ if AEMFC technology is to address the lightduty or heavy-duty vehicle markets.

Similarly, there was some discussion about whether an ASR target was needed and, if so, whether it could be less demanding than that for a PEM system. Due to other advantages, such as lower PGM loading, the overall system cost may be lower even with poorer ASR. It was also mentioned that even with higher membrane resistance, there might be sufficient power density to have a lower cost. 
Durability targets and protocols were discussed. Current AEMFC durability milestones have not been met at the loading of $0.1 \mathrm{mg} / \mathrm{cm}^{2}$ and because no one has operated an AEMFC for 2,000 hours, but there have been several cells demonstrated at $500 \mathrm{~h}$ and a few at 1,000 h that did not undergo catastrophic cell failure. The initial position was to start with the current accelerated stress test protocols for PEM MEAs and adopt them for AEMFCs. Looking more closely at the existing PEM accelerated stress tests, the consensus was that RH cycling as a durability stressor was not applicable for AEMFC applications, as AEMFCs cannot currently be operated at low $\mathrm{RH}$ conditions. The MEA chemical stability test (an open circuit voltage [OCV] hold test) was thought to be relevant and could be an interesting stressor (especially for adsorption of ionomer in catalyst layers, perhaps by testing impedance). However, it was stated that as you draw more current, AEMFC stability tends to improve, and that oxidative decomposition rate of the cathode ionomer is high for some polymers at voltages near OCV. These high potentials can be avoided with system mitigation strategies, as is being done in PEMFC systems. Some still appeared to believe an OCV hold test would be a good demonstration. However, others in the group would prefer the test not be prescribed without some current flowing; instead they would prefer to meet target durability at a specified (low) current density. Conditions for the OCV or high voltage hold were also discussed. For the PEM system, the OCV hold is at 30\%/30\% RH for $500 \mathrm{~h}$. For AEM the hold should be at higher RH. However, because the goal is for the test to be accelerated and lower RH will accelerate known degradation modes in AEM, there was some discussion of what RH should be utilized. Conditions of $80 \% \mathrm{RH}, 70 \% \mathrm{RH}$ at $90^{\circ} \mathrm{C}$, and $60-70 \% \mathrm{RH}$ at $\geq 80^{\circ} \mathrm{C}$ were proposed. It was noted that hot spots at $80^{\circ} \mathrm{C}$ will still approach or exceed $90^{\circ} \mathrm{C}$. It was suggested that the AEM test use the same passing criteria as the PEM test-less than $20 \%$ decrease in OCV after the $500 \mathrm{~h}$ hold.

Potential cycling tests were also considered to be relevant for AEMFCs. However, due to the current status of AEMFC durability, it was suggested that 10,000 cycles with $<40 \%$ loss (rather than 30,000 cycles for PEM) would be appropriate for the catalyst durability cycling test (0.6$0.95 \mathrm{~V}$ ) at this stage.

The breakout group discussed $\mathrm{CO}_{2}$ tolerance and agreed that it would be too difficult to run on straight air with $\mathrm{CO}_{2}$, and some $\mathrm{CO}_{2}$ scrubbing will be needed. Even at $95^{\circ} \mathrm{C}$, losses due to $\mathrm{CO}_{2}$ will be $100-150 \mathrm{mV}$ at a minimum. Some literature has shown that reducing $\mathrm{CO}_{2}$ levels to $5 \mathrm{ppm}$ is still not sufficient, and it was stated that some existing modeling has suggested that scrubbing $<1 \mathrm{ppm} \mathrm{CO}_{2}$ will be required to minimize $\mathrm{CO}_{2}$ effects, even for an operating temperature of $95^{\circ} \mathrm{C}$. Currently, most AEM polymers are only stable up to $80^{\circ} \mathrm{C}$. While complete removal of $\mathrm{CO}_{2}$ is probably not possible, there should be some $\mathrm{CO}_{2}$ threshold stated for testing in $\mathrm{CO}_{2}-$ scrubbed air. The participants believed we should not specify the method for $\mathrm{CO}_{2}$ scrubbing because other DOE offices are looking at high-efficiency $\mathrm{CO}_{2}$ removal membranes and other methods for scrubbing $\mathrm{CO}_{2}$. For AEMFCs, due to the low tolerance to $\mathrm{CO}_{2}$, a two-stage system might be needed: a bulk system to remove the majority of $\mathrm{CO}_{2}$ and then a system to polish to a lower level. DOE may want to consider some work on removal of $\mathrm{CO}_{2}$ as an ancillary effort and should consider milestones and targets $\left(\mathrm{CO}_{2}\right.$ level) for $\mathrm{CO}_{2}$ removal subsystems for AEMFCs with enough specifications to make comparisons between systems easier. There may be engineering approaches that do not have as large an impact on the stack, similar to an air bleed to improve CO tolerance for PEM reformate systems, but as yet are unknown. At the system level, the air has to come in, so the cell test should be on air scrubbed of $\mathrm{CO}_{2}$. At present, it is hard to pick a limit for $\mathrm{CO}_{2}$ tolerance. DOE should do some analysis to see what the $\mathrm{CO}_{2}$ level needs to 
be for an interim target. The $\mathrm{CO}_{2}$ level should be related to the rated power target, $10 \%$ degradation at $0.65 \mathrm{~V}$. It is believed this will be similar to previous sulfur targets for the development of reformate-fueled fuel cells. Tests could be done cycling between $\mathrm{CO}_{2}$-free air and air doped with low levels of $\mathrm{CO}_{2}$ to see the impact. The ISO tolerance for $\mathrm{CO}_{2}$ in $\mathrm{H}_{2}$ is 2 ppm, so tests should be done to match the performance loss from $\mathrm{CO}_{2}$ in $\mathrm{H}_{2}$ at 2 ppm levels, as the effect should be the same. One should consider the voltage loss at a current density of $\sim 1.5$ $\mathrm{A} / \mathrm{cm}^{2}$ at $0.65 \mathrm{~V}(65 \mathrm{mV}$ loss after $2 \mathrm{ppm} \mathrm{CO} 2)$. This must be measured at the new steady state after equilibration with the $2 \mathrm{ppm} \mathrm{CO}_{2}$. There should be no need to add a degradation component to it. Others indicated that in a duty cycle there might be some points where $\mathrm{CO}_{2}$ tolerance is higher and steady state at rated power may be the worst case for $\mathrm{CO}_{2}$ tolerance, so they suggested demonstrating over a duty cycle for $1,000 \mathrm{~h}$. After discussion, it was decided that going to steady state for the measurements is easier for the near term. It was also suggested that a test be run in the air $\left(400 \mathrm{ppm} \mathrm{CO}_{2}\right)$ for $1,000 \mathrm{~h}$ to see if any performance remains.

It was recognized that all the MEA targets need to be met with the same MEA. There was some question of the applicability of catalyst kinetics targets for AEMFCs, and there was a suggestion to scrap the HOR/ORR kinetic activity targets and replace them with an efficiency target at a specified loading and current density.

New suggested milestones and targets are shown in Table 2.

Table 2. Suggested Milestones and Targets for AEMFCs

\begin{tabular}{|c|c|}
\hline \multicolumn{2}{|c|}{ Proposed Milestones } \\
\hline 2021 & $\begin{array}{l}\text { Efficiency: } 100 \mathrm{~mW} / \mathrm{cm}^{2} \text { performance at } 0.8 \mathrm{~V}\left(\mathrm{~T} \geq 80^{\circ} \mathrm{C}\right) \text { with } 0.2 \mathrm{mg} \mathrm{PGM}_{\mathrm{m}} / \mathrm{cm}^{2}, \mathrm{P} \\
\leq 250 \mathrm{kPa}\end{array}$ \\
\hline 2022 & $\begin{array}{l}\text { AEMFC initial performance } 0.65 \mathrm{~V} \text { at } 1,000 \mathrm{~mA} / \mathrm{cm}^{2} \text { on } \mathrm{H}_{2} / \mathrm{O}_{2} \text { (maximum pressure of } \\
1.5 \mathrm{~atm} \text { ) in MEA with total }<0.2 \mathrm{mgPGM} / \mathrm{cm}^{2} \text { and }<10 \% \text { voltage degradation over } \\
1,000 \mathrm{~h}, \mathrm{~T}>80^{\circ} \mathrm{C}\end{array}$ \\
\hline 2023 & $\begin{array}{l}\mathrm{CO}_{2} \text { tolerance: }<65 \mathrm{mV} \text { loss for steady state operation at } 1.5 \mathrm{~A} / \mathrm{cm}^{2} \text { in } \mathrm{H}_{2} / \text { air } \\
\text { scrubbed to } 2 \mathrm{ppm} \mathrm{CO} 2\end{array}$ \\
\hline 2024 & $\begin{array}{l}\text { Catalyst durability: } \mathrm{H}_{2} / \mathrm{CO}_{2} \text {-scrubbed air after accelerated stress test }<40 \% \text { loss } \\
\text { after } 10,000 \text { cycles from } 0.6 \mathrm{~V} \text { to } 0.95 \mathrm{~V} \\
\text { Membrane durability: } 1,000 \mathrm{~h} \mathrm{OCV} \text { hold at } 70 \% \mathrm{RH} \text { and } \geq 80^{\circ} \mathrm{C}\end{array}$ \\
\hline 2025 & $\begin{array}{l}1 \mathrm{~W} / \mathrm{cm}^{2} \text { at } 0.65 \mathrm{~V} ; \mathrm{H}_{2} / \mathrm{CO}_{2} \text {-free air with total PGM loading }<0.125 \mathrm{mg} / \mathrm{cm}^{2}, \mathrm{~T}>80^{\circ} \mathrm{C} \text {, } \\
\mathrm{P} \leq 250 \mathrm{kPa}\end{array}$ \\
\hline 2030 & $\begin{array}{l}\text { AEMFC peak power performance }>600 \mathrm{~mW} / \mathrm{cm}^{2} \text { under } \mathrm{H}_{2} / \text { air (maximum pressure of } \\
1.5 \mathrm{~atm} \text { ) in PGM-free MEA }\end{array}$ \\
\hline Ultimate & $1 \mathrm{~W} / \mathrm{cm}^{2}$ at rated power $\left(\sim 0.65 \mathrm{~V}\right.$ at $\left.95^{\circ} \mathrm{C}\right), \mathrm{PGM}$-free $\mathrm{MEA}, \mathrm{T} \geq 80^{\circ} \mathrm{C}, \mathrm{P} \leq 250 \mathrm{kPa}$ \\
\hline
\end{tabular}




\section{References}

The list of references supports the text of the report but is by no means intended to be exhaustive.

ARPA-E. 2016. "Integration and Optimization of Novel Ion Conducting Solids (IONICS)." Funding Opportunity Announcement (FOA) DE-FOA-0001478. https://arpa-e-

foa.energy.gov/Default.aspx?Archive=1\#FoaIdd3b62d65-4754-4cb4-b879-d2e6cea654eb.

Dillard, David A., Yongqiang Li, Jacob R. Grohs, Scott W. Case, Michael W. Ellis, Yeh-Hung Lai, Michael K. Budinski, and Craig S. Gittleman. 2009. "On the Use of Pressure-Loaded Blister Tests to Characterize the Strength and Durability of Proton Exchange Membranes." J. Fuel Cell Sci. Technol. 6 (3): 031014. https://doi.org/10.1115/1.3007431.

FCTO (Fuel Cell Technologies Office). 2017. “3.4 Fuel Cells, 2016.” Fuel Cell Technologies Office Multi-Year Research, Development, and Demonstration Plan. https://www.energy.gov/sites/prod/files/2017/05/f34/fcto myrdd fuel cells.pdf

FCTO. 2016. 2016 Alkaline Membrane Fuel Cell Workshop Summary Report. Washington, DC: U.S. Department of Energy Office of Energy Efficiency and Renewable Energy. https://www.energy.gov/eere/fuelcells/downloads/2016-alkaline-membrane-fuel-cell-workshop.

Grohs, Jacob R., Yongqiang Li, David A. Dillard, Scott W. Case, Michael W. Ellis, Yeh-Hung Lai, Craig S. Gittleman. 2010. "Evaluating the time and temperature dependent biaxial strength of Gore-Select ${ }^{\circledR}$ series 57 proton exchange membrane using a pressure loaded blister test." $J$. Power Sources 195 (2): 527-531. https://doi.org/10.1016/j.jpowsour.2009.07.054.

Pivovar, Bryan. 2012. 2011 Alkaline Membrane Fuel Cell Workshop Final Report. Golden, CO: National Renewable Energy Laboratory. NREL/BK-5600-54297.

https://www.energy.gov/eere/fuelcells/downloads/2011-alkaline-membrane-fuel-cell-workshop.

Pivovar, Bryan. 2006. Alkaline Membrane Fuel Cell Workshop Final Report. Los Alamos, NM: Los Alamos National Laboratory. https://www.energy.gov/sites/prod/files/2014/03/f12/amfc_dec2006_workshop_report.pdf.

Yongqiang Li, David A. Dillard, Scott W. Case, Michael W. Ellis, Yeh-Hung Lai, Craig S. Gittleman, and Daniel P. Miller. 2009. "Fatigue and creep to leak tests of proton exchange membranes using pressure-loaded blisters." J. Power Sources 194 (2): 873-879. https://doi.org/10.1016/j.jpowsour.2009.06.083. 